\title{
Biomineralization of Amorphous Calcium Carbonate (ACC) is widespread in Bacteria
}

KARIM BENZERARA ${ }^{1}$, BIDAUd CECILE ${ }^{1,2}$, BOLZONI ROMAIN $^{2}$, ElODIE DUPRAT ${ }^{1}$, MENGUY NICOLAS ${ }^{1}$, CAROLINE L. MONTEIL ${ }^{2}$, CHRISTOPHER T. LEFEVRE ${ }^{2}$

${ }^{1}$ Sorbonne Université, Muséum National d'Histoire Naturelle, UMR CNRS 7590, IRD. Institut de Minéralogie, de Physique des Matériaux et de Cosmochimie (IMPMC), 4 Place Jussieu, 75005 Paris, France.

${ }^{2}$ Aix-Marseille University, CNRS, CEA, UMR7265 Institute of Biosciences and Biotechnologies of Aix-Marseille, CEA Cadarache, F-13108 Saint-Paul-lez-Durance, France

Bacterial biomineralization of $\mathrm{CaCO}_{3}$ has been known for more than a century. For a long time, it has been mostly considered as an extracellular process induced secondarily by chemical shifts created by the metabolic activity of cells and/or influenced by the production of molecules favoring crystal nucleation. In that context, the controlled mineralization of intracellular $\mathrm{CaCO}_{3}$ by the gammaproteobacterium Achromatium has long remained the exception. More recently, several cyanobacterial species have also been shown to biomineralize $\mathrm{CaCO}_{3}$ intracellularly. However, while the most recent studies have suggested that the mineral phase formed by Achromatium is calcite, cyanobacteria seem in contrast to form amorphous $\mathrm{Ca}$ carbonates (ACC), questioning the similarities of these biomineralization pathways.

Here we will present recent findings from a field-based study in Lake Pavin, France, evidencing diverse bacterial populations forming intracellular ACC. This include a population of Achromatium cells and populations of magnetotactic bacteria. First, we will report Raman analyses which clearly demonstrate that $\mathrm{CaCO}_{3}$ granules in all these bacteria, including Achromatium, are composed of ACC and not calcite. We we will explain why there have been some confusion and misinterpretations about this point in past studies. Moreover, we will describe the ultrastructure and ecology of the ACC-biomineralizaing magnetotactic bacteria and show that they belong to a new bacterial class where biomineralization of intracellular ACC occurs. Overall, this suggests that biomineralization of intracellular ACC is a widespread capability in Bacteria and has been likely totally overlooked. Last, we will discuss the potential significance of intracellular ACC biomineralization for local geochemical cycles, as well as its potential functions for the microorganisms. 